\title{
EMBEBIÇÃO E POSIÇÃO DA SEMENTE NA GERMINAÇÃO DE CLONES DE PORTA-ENXERTOS DE CAJUEIRO-ANÃO-PRECOCE ${ }^{1}$
}

\author{
JOSÉ RIBAMAR GUSMÃO ARAUJO², MÁRCIACRISTINA MENDES CERQUEIRA³, \\ JOSIANE MARLLE GUISCEM ${ }^{4}$, MOISÉS RODRIGUES MARTINS ${ }^{4}$, \\ FRANCISCO NÓBREGA DOS SANTOS ${ }^{4}$, MARIA CRISTINA SOUSA MENDONÇA ${ }^{4}$
}

RESUMO- O presente trabalho teve por objetivo avaliar a embebição e a posição de semeadura no processo de germinação de sementes de cajueiro-anão-precoce, em condições de telado. O experimento foi conduzido na Fazenda Escola São Luís, da Universidade Estadual do Maranhão, São Luís-MA. Utilizou-se o esquema fatorial 2 × 3 x 2, no delineamento experimental em blocos casualizados e quatro repetições, com 15 sementes por parcela, semeadas em sacolas plásticas. Os tratamentos resultaram da combinação de dois clones (CCP .06 e CCP 76), três tratamentos de embebição (água, sacarose e natural ) e posição da semente (peduncular e dorsal) por ocasião da semeadura. Verificou-se que, aos 22 dias após a semeadura, o clone CCP 76, com as sementes embebidas em água e semeadas na posição peduncular, apresentou níveis satisfatórios de germinação (100\%), resultando em maior eficiência do processo de germinação das sementes e precocidade em termos de estabilização da germinação (cerca de 16 dias). Os tratamentos de embebição com sementes na posição peduncular não apresentaram efeito significativo sobre a emergência das plântulas dos dois clones, mas influenciaram nos valores do índice de velocidade de emergência, onde os tratamentos com água e a posição peduncular proporcionaram maior velocidade de emergência, independentemente dos clones estudados.

Termos para indexação: Anacardium occidentale L.;propagação; emergência de plântulas.

\section{IMBIBITION AND POSITION OF SEED ON THE GERMINATION OF SEEDLINGS OF DWARF-PRECOCIOUS CASHEW ROOTSTOCKS}

\begin{abstract}
The present work aimed to evaluate the imbibition and the sowing position on the process of seed germination of dwarf cashew-precocious rootstocks. The experiment was carried out on São Luís Experimental Farm of the Maranhão State University, Brazil. The experimental model was a factorial design $2 \times 3 \times 2$ in randomized blocks and four replications, with 15 seeds per plot, sowed in plastic bags. The treatments resulted from the combination of two cashew clones (CCP 06 and CCP 76), three treatments of imbibition (water, sucrose and natural) and seed position (hilo and dorsal) before sowing. According to the obtained results, it was verified that up to 22 days after sowing the clone CCP 76 with seeds soaked in water and sowed in the hilo position, presented satisfactory levels of germination (100\%), resulting in larger efficiency of the seed germination process and precocity in terms of stabilization of the germination (about 16 days). The treatments of imbibition at hilo position did not present a significant effect on the seedlings emergence of two clones, but they influenced the emergence speed index, in which the treatments using water and hilo position promoted higer index, regardless of the tested clones.
\end{abstract}

Index terms: Anacardium occidentale L; propagation; seedlings emergence.

\footnotetext{
${ }^{1}$ (Trabalho 083-08). Recebido em: 03-04-2008. Aceito para publicação em: 25-03-2009.

${ }^{2}$ Prof $^{\circ}$ Dept $^{\circ}$ de Fitotecnia e Fitossanidade /UEMA, C. Postal 09 - AG Tirirical, 65.098-970 São Luís-MA . E-mail: gusmao@elo.com.br

${ }^{3}$ Estudante de Agronomia/UEMA, bolsista PIBIC/CNPq - C. P. 09 - AG Tirirical, 65.098-970. São Luís-MAmarciaccerqueira@hotmail.com; jmguiscem@hotmail.com; martinsbeq@yahoo.com.br; nobrega@cca.uerna.br ${ }^{4}$ Prof $^{\circ}$ Dept $^{\circ}$ de Fitotecnia e Fitossanidade /UEMA, C. Postal 09 - AG Tirirical, 65.098-970. São Luís-MA. emendonca98@yahoo.com.br
} 


\section{INTRODUÇÃO}

O Estado do Maranhão ocupa a quarta posição na produção de castanha-de-caju no Nordeste brasileiro, mas respondendo por apenas 3 $\%$ do total. No entanto, o Estado apresenta $75 \%$ da sua área total com aptidão para o cultivo do cajueiro, sendo esta a maior do Nordeste. Neste cenário, o Maranhão poderá colocar-se, a médio prazo, entre os principais estados produtores de castanha-decaju e derivados (Araujo \& Silva, 1995; Araujo, 1998; Aguiar, 2000).

O cajueiro ocupa lugar de destaque entre as plantas frutíferas tropicais no Nordeste em face da crescente comercialização de seus produtos, no entanto, para áreas novas, existem alguns entraves no tocante à obtenção de mudas para plantio que precisam ser superados, passando pela disponibilidade de sementes de boa qualidade e obtenção de plantas vigorosas e mais precoces em nível de viveiristas.

Parece possível associar-se o tratamento de embebição com a posição da semente no leito de semeadura, visando a estabelecer maior praticidade do processo e obtenção de maior percentagem de plântulas normais, resultando em elevado aproveitamento de plantas para a enxertia.

No Maranhão, é recente a introdução do cajueiro-anão-precoce, havendo desconhecimento do comportamento ecológico e produtivo dos clones, com o agravante de que muitos pomares são formados de pés-francos.

O cajueiro-anão-precoce é também conhecido por cajueiro-de-seis-meses, e caracteriza-se pelo porte baixo, altura abaixo de $4 \mathrm{~m}$, copa homogênea, com variação do tamanho de 5,0 m a 6,0 m, diâmetro do caule e envergadura bem inferiores ao do tipo comum, e o florescimento inicia-se ao 6-18 meses razão da citada precocidade (Barros et al., 1998). Dois clones de cajueiro-anão-precoce ganharam maior expressão quando utilizados como porta-enxertos. O clone CCP 06 possui pedúnculo de cor amarela, com $80 \mathrm{~g}$, castanha com peso médio de 6,7 g e amêndoa despeliculada com média de $1,7 \mathrm{~g}$ com umidade natural, e o clone CCP 76 possui pedúnculo de cor vermelho-clara, castanha com 9,3 g de peso médio e amêndoa despeliculada com 24 g com umidade natural (Barros et al., 1993).

A densidade da castanha é um valor que pode ser tomado com critério prático para assegurar boa germinação e estabelecimento da plântula, sendo as castanhas de grupo de maior densidade as que apresentam maior taxa de germinação, melhor crescimento da parte aérea e maior peso total. Segundo esses autores, pesquisas mostram que castanhas de maior densidade apresentam emergência e vigor sempre superiores (Cavalcanti Júnior et al., 2002).

De acordo com Auckland (1961), sementes de maior densidade apresentam germinação melhor, além de originarem plântulas mais vigorosas. O peso da semente influencia na absorção de água, havendo correlação positiva entre velocidade e porcentagem de germinação com a absorção de água.

Dadas as características de reprodução do cajueiro e a elevada segregação genética resultante do plantio de sementes, reduzindo o potencial de produção dos pomares, tem sido recomendado o plantio de clones selecionados de cajueiro-anão (Barros et al., 1993). O porta-enxerto mais indicado é o originário de sementes do CCP 06 (Cavalcanti Júnior \& Chaves, 2001).

Para os porta-enxertos, as sementes devem ser coletadas de plantas de cajueiro-precoce produtivas, vigorosas e livres de doenças e pragas; além disso, no caso de sementes armazenadas, recomenda-se mergulhá-las em água por uma noite antes da semeadura, para a pré-embebição das sementes, e a semeadura da semente deve ser realizada diretamente no saco de plástico, na posição vertical, com a ponta voltada para baixo e enterrada a uma profundidade máxima de $3 \mathrm{~cm}$ abaixo da superfície do substrato (Barros et al., 1993).

Quando a semeadura é realizada superficial, a posição da semente não interfere na emergência da plântula, mas à proporção que vai aprofundando, a semente deve ser posicionada na vertical com o ponto de inserção (hilo) castanha/pedúnculo voltado para cima (Cavalcanti Júnior et al., 2002).

Vários estudos têm sido realizados, para avaliar a influência de diferentes soluções de embebição de sementes na germinação e nas características das plântulas (Bovi, 1990; Carneiro et al., 2002), assim como estudos a respeito da posição de semeadura da castanha (Cavalcanti Júnior et al., 2002). Na busca de recomendações práticas aos viveiristas, o presente trabalho visou a avaliar, em condições de telado, a embebição e a posição da semente na semeadura, no processo de germinação de sementes de dois cajueiros-anões-precoces.

\section{MATERIAL E MÉTODOS}

O trabalho foi conduzido em condições de viveiro tipo telado, localizado na área experimental da Fazenda Escola São Luís, da Universidade 
Estadual do Maranhão, em São Luís-MA. O nível de sombreamento do viveiro foi mantido a $50 \%$.

O experimento foi instalado no esquema fatorial $2 \times 3 \times 2$, no delineamento de blocos casualizados, com quatro repetições, totalizando 48 parcelas experimentais, sendo os fatores dois clones (CCP 06 e CCP 76), três tratamentos de embebição (água, sacarose e natural) e duas posições da semente (peduncular e dorsal). Cada parcela foi constituída de 15 sacolas de polietileno preto de 1,8 litro (dimensões de 28 x $15 \mathrm{~cm}$ e 0,15 mm de espessura), contendo uma semente por embalagem, e o substrato foi composto de mistura de solo agrícola e resíduo de Fava D'anta (Dimorphandra mollis), na proporção 3:1 (v/v). Foram utilizadas sementes de dois clones de cajueiro-anão-precoce CCP 06 e CCP 76, provenientes do CNPAT Embrapa, Fortaleza-CE. A preferência por esses clones ocorreu em função de eles induzirem a formação de plantas de porte mais baixo e com precocidade, sem comprometerem as demais características do enxerto.

O tratamento com embebição das sementes foi realizado colocando-se as sementes de cada clone sob imersâo em água por 24 horas e em solução de sacarose a $15 \%$ por 24 horas. As sementes foram selecionadas em relação a sua densidade na água, e aquelas que afundaram, foram retiradas para semeadura. No tratamento de embebição em solução de sacarose, em virtude da maior densidade da solução, a grande maioria das sementes (viáveis e inviáveis) flutuaram, e estas foram retiradas para semeadura, restando poucas unidades no fundo do recipiente. Outra parte das sementes não sofreu imersão (tratamento natural).

Por ocasião da semeadura, as sementes foram colocadas em duas posições: semente na posição peduncular (com hilo para cima) e semente na posição dorsal (com “ombro” para cima).

Aos 5 dias após a semeadura, iniciou-se a avaliação do número de plântulas emergidas, com intervalos de 2 dias, até completar 30 dias, sendo determinada a percentagem de emergência de cada tratamento, nos diferentes períodos avaliados. Como padrão, considerou-se semente com plântula emergida, aquela cuja noz se apresentou aberta, e o ápice caulinar, visível. O tempo de estabilização da emergência foi determinado por meio da contagem do tempo desde a semeadura até o momento em que a taxa de sementes com plântula emergida mantevese inalterada em duas contagens consecutivas.

Para o cálculo do índice de velocidade de emergência de sementes (IVE), adotou-se fórmula de Maguire (1962). Os parâmetros avaliados foram submetidos à análise de variância, e as médias dos tratamentos foram comparadas pelo teste de Tukey. Os dados de percentagem de germinação sofreram transformação em arc.sen $\sqrt{\mathrm{x}+0,5}$ visando a uniformizar a variância (Banzatto \& Kronka, 1989).

\section{RESULTADOSE DISCUSSÃO}

Neste estudo, foi observado que a emergência das sementes iniciou 10 dias após a semeadura. Para Cavalcanti Júnior et al. (2002), a germinação de sementes de cajueiro-anão-precoce inicia-se a partir do $10^{\circ}$ dia após a semeadura e prolonga-se até o $25^{\circ}$ dia, contudo $80 \%$ da germinação ocorre entre o $12^{\circ} \mathrm{e}$ o $20^{\circ}$ dia após a semeadura. Na Tabela 1 , referente aos resultados de germinação aos 12 dias após a semeadura (DAS), verifica-se que houve efeito significativo dos fatores estudados, os clones, tratamento de embebição e posição da semente.

Nesta fase, somente o clone CCP 76 apresentou taxa de emergência de plântulas, havendo influência significativa e valores mais altos para o tratamento cujas sementes sofreram imersão em água e foram semeadas na posição peduncular. A diferença entre clones (ausência de emergência no Clone CCP 06 aos 12 dias), possivelmente, resultou do vigor inicial da semente ou de características intrínsecas da variedade, já que as sementes de ambos os clones foram submetidas às mesmas condições e tratamentos (Tabela 1).

O tratamento com imersão em água mostrouse superior à sacarose e natural, independentemente da posição da semente no leito de semeadura, conforme observado no clone CCP 76. A absorção de água representa o passo inicial do processo de germinação, onde a semente se caracteriza pelo seu intumescimento (Nakagawa, 1999). Em decorrência da embebição de água, ocorre ativação do metabolismo do embrião, que redunda na emersão da radícula (Bewley \& Black, 1994); a pré-embebição em água realizada neste trabalho pode ter influenciado a diferença verificada na emergência inicial, em relação ao tratamento natural, mesmo tendo-se passado doze dias da semeadura (Tabela 1).

Em relação à posição de semeadura, a peduncular proporcionou maior percentagem de emergência na avaliação aos 12 DAS (Tabela 1). Essa posição parece favorecer anatomicamente o desenvolvimento do eixo embrionário (radículaepicótilo), associado ao fototropismo positivo da plântula na emergência. Carneiro (2003) recomenda que as sementes sejam plantadas com o hilo voltado para cima (posição peduncular), com uma inclinação 
de mais ou menos $40^{\circ}$, o que assegura melhor germinação e formação do caule ereto. Também outros autores recomendam a semeadura de cajueiro-anãoprecoce na posição vertical, equivalente neste trabalho, à posição peduncular (Barros et al., 1993; Corrêa et al.,1995).

Aos 22 DAS, período caracterizado pela estabilização do processo de germinação (Tabela 2), observou-se que não houve diferença significativa entre os tratamentos de imersão das sementes dos clones considerando a posição peduncular. Somente na posição dorsal e para os dois clones, verificaramse diferenças significativas entre os tratamentos de imersão, sempre vantajosa à embebição em água. Isso significa que a posição peduncular é tão favorável ao processo de germinação de sementes de cajueiroanão-precoce que anula os efeitos dos tratamentos adicionais de imersão, concordando com observações de Cavalcanti Júnior \& Chaves (2002), que recomendam a semeadura na posição vertical.

Quanto aos clones, a emergência foi maior no clone CCP 76, quando comparado com o clone CCP 06, alcançando a taxa máxima (100,0 \%) nos tratamentos de imersão em água. A menor taxa média de emergência foi observada no clone CCP 06 (natural e posição dorsal), com 88,3 \%. Assim, pode-se inferir que as condições de pré-embebição favoreceram a germinação e a expressão do vigor da semente de cajueiro.

Com relação aos valores do Índice de Velocidade de Emergência (IVE) (Tabela 3), constatouse que houve diferenças estatísticas significativas entre as médias dos tratamentos de embebição e também entre as médias dos tratamentos de posição, com os valores mais altos para o clone CCP 76, confirmando o maior vigor de suas sementes. Dentro de cada clone, verificaram-se diferenças significativas nos resultados de IVE entre as posições peduncular e dorsal, com valores superiores da posição peduncular. Também em relação aos tratamentos de imersão, os resultados foram significativos para a pré-embebição em água, seguido da solução de sacarose, e ambos diferindo da testemunha (natural).

Levando em conta a combinação dos três fatores, o maior valor de IVE $(1,11)$ foi observado no clone CCP 76, semente embebida em água e semeada na posição peduncular, confirmando a eficiência destes procedimentos e a baixo custo na preparação de mudas vigorosas de cajueiro. O tratamento de pré-embebição das sementes no início do processo de germinação repercutiu até o final do ensaio, aumentando o IVE. Mais do que as diferenças entre clones, atribuídas às caraterísticas genéticas e fisiológicas, o processo de produção de mudas de cajueiro em sua fase incial (sementeira) é nitidamente favorecido pelo tratamento de pré-embebição das sementes em água, seguido da semeadura na posição peduncular. A velocidade de germinação é um dos conceitos mais antigos de vigor de sementes (Nakagawa, 1999), que pode ser influenciado pelo genótipo e pelas condições favoráveis.

O período de tempo necessário para que ocorresse a estabilização do processo de emergência das plântulas ao final das avaliações, em função dos tratamentos-clone, embebição e posição da semente podem ser visualizados na Figura 1. Considerando os três fatores envolvidos, o tempo médio de estabilização da germinação da semente de cajueiroanão- precoce, nas condições experimentais, foi de 20,9 dias, confirmando observações de Corrêa et al. (1995), em que as sementes podem alcançar a emergência até o limite dos 20 dias ou prolongar-se até o $25^{\circ}$ dia após a semeadura (Cavalcanti Júnior et al., 2002).

A maior antecipação do processo foi observado no clone CCP 76, com sementes na posição peduncular e pré-embebidas em água, cuja estabilização da emergência ocorreu aos 16 dias, contra os 26 dias verificados no clone CCP 06 (semente natural/posição dorsal). Os tempos de estabilização de 16 dias e 20 dias para os clones CCP 76 e CCP 06, respectivamente, podem ser tomados como limites para se selecionarem plântulas vigorosas para a formação de mudas considerando esses porta-enxertos e a melhor combinação de tratamentos. 


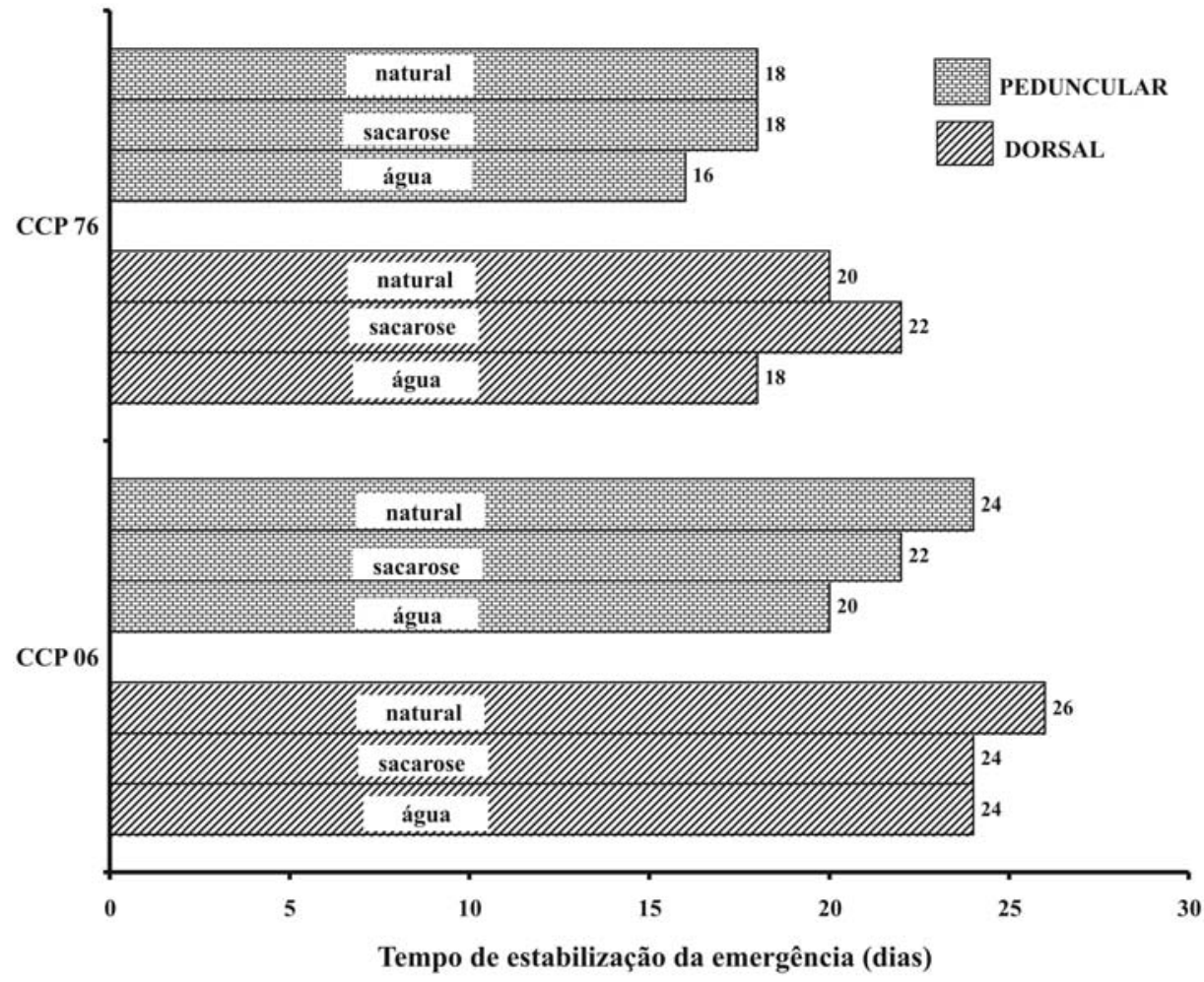

FIGURA 1- Tempo para a estabilização da emergência de plântulas de clones de cajueiro-anão-precoce (CCP 06 e CCP 76), em função do tratamento de embebição e posição da semente. São Luís-MA, 2003.

TABELA 1- Médias de emergência (\%) de sementes de dois clones de cajueiro-anão-precoce (CCP 06 e CCP 76), submetidos aos tratamentos de imersão e posição das sementes, aos 12 dias após a semeadura. São Luís-MA, 2003.

\begin{tabular}{lcccc}
\hline $\begin{array}{l}\text { Tratamento de } \\
\text { Imersão }\end{array}$ & Peduncular & Dorsal & Peduncular & Dorsal \\
\hline Água & 0,0 & 0,0 & 34,9 a A & 24,9 a B \\
Sacarose & 0,0 & 0,0 & $18,3 \mathrm{~b} \mathrm{~A}$ & $6,6 \mathrm{~b} \mathrm{~B}$ \\
Natural & 0,0 & 0,0 & $0,0 \mathrm{c} \mathrm{A}$ & $0,0 \mathrm{c} \mathrm{A}$ \\
\hline
\end{tabular}

CV $(\%)=26,21$

Médias seguidas das mesmas letras minúsculas na coluna e maiúsculas na linha não diferem entre si, pelo teste de Turkey, a $5 \%$ de probabilidade de erro.

TABELA 2- Médias de emergência (\%) de sementes de dois clones de cajueiro-anão-precoce (CCP 06 e CCP 76), submetidos aos tratamentos de imersão e posição das sementes, aos 22 dias após a semeadura. São Luís-MA, 2003.

\begin{tabular}{lcccc}
\hline $\begin{array}{l}\text { Tratamento de } \\
\text { Imersão }\end{array}$ & Peduncular & Dorsal & Peduncular & Dorsal \\
\hline Água & 96,6 a A & 94,9 a A & 100,0 a A & 100,0 a A \\
Sacarose & 98,3 a A & 94,9 a A & 98,3 a A & 94,9 b A \\
Natural & 96,6 a A & 88,3 b B & 98,3 a A & 100,0 a A \\
\hline
\end{tabular}

$\mathrm{CV}(\%)=4,81$

Médias seguidas das mesmas letras minúsculas na coluna e maiúsculas na linha não diferem entre si, pelo teste de Turkey, a $5 \%$ de probabilidade de erro. 
TABELA 3 - Velocidade de Emergência de sementes de dois clones de cajueiro-anão-precoce, submetidos a tratamentos de imersão e posição de semeadura. São Luís-MA, 2003.

\begin{tabular}{lcccc}
\hline Tratamento de & \multicolumn{2}{c}{ CCP 06 } & \multicolumn{2}{c}{ CCP 76 } \\
Imersão & Peduncular & Dorsal & Peduncular & Dorsal \\
\hline Água & 0,94 a A & 0,88 a B & 1,11 a A & 1,04 a B \\
Sacarose & 0,94 a A & 0,85 a B & 1,04 b A & 0,90 b B \\
Natural & $0,89 \mathrm{~b} \mathrm{~A}$ & 0,78 b B & 0,95 c A & 0,92 b A \\
\hline
\end{tabular}

CV $(\%)=5,01$
Médias seguidas das mesmas letras minúsculas na coluna e maiúsculas na linha não diferem entre si , pelo teste de Turkey, a $5 \%$ de probabilidade de erro.

\section{CONCLUSÃO}

As sementes do clone CCP 76, pré-embebidas em água e semeadas na posição peduncular, apresentaram níveis satisfatórios de emergência das plântulas (100\%). Recomenda-se o tratamento de préembebição das sementes em água por 24 horas, por ter proporcionado maior velocidade e estabilização mais rápida no processo de germinação.

\section{REFERÊNCIAS}

AGUIAR, M. J. N. Zoneamento pedoclimático para a cultura do cajueiro (Anacardium occidentale L.) para o Estado do Maranhão. Fortaleza: EMBRAPACNPAT, 2000. 42p.

ARAÚJO, J.P. Desafios e perspectivas agroindustriais no Maranhão. São Luís: GEPLAN, 1998. 43p.

ARAÚJO, J.P.P.; SILVA,V.V. (Orgs.). Cajucultura: modernas técnicas de produção. Fortaleza: EMBRAPA-CNPAT, 1995. 292p.

AUCKLAND, A.K. The influence of seed quality on early growth of cashew. Tropical Agriculture, New Delhi, v.38, n.1, p.57-67, 1961.

BANZATTO, D.A.; KRONKA, S.N. Experimentação agrícola. Jaboticabal: FUNEP/UNESP, 1989. 247 p.

BARROS, L.M.;PAIVA, J.R.; CAVALCANTI, J.J.V. Cajueiro-anão-precoce: melhoramento genético estratégias e perspectivas. Biotecnologia Ciência \& Desenvolvimento, Brasília, n.6, p. 18-21, 1998.

BARROS, L.M.; PIMENTEL, C.R.M.; CORREA, M.P.F., MESQUITA, A.L.M. Recomendações Técnicas para a cultura do cajueiro-anão-precoce. Fortaleza: EMBRAPA-CNPAT, 1993. 65p. (Circular Técnica, 1).
BEWLEY, J. D.; BLACK, M. Seeds: physiology of development and germination. 2. ed. New York: Plenum Press, 1994. 445p.

BOVI, M.L.A. Pré-embebição em água e porcentagem e velocidade de emergência de sementes de palmiteiro. Bragantia, Campinas, v.49, n.1, p.11-22, 1990.

CARNEIRO, J.H.M. Germinação de sementes de milho (Zea Mays L.): posição da semente e substrato, sobre a incidência de plântulas anormais em duas cultivares. 2003. 35 f. Monografia (Trabalho em Graduação em Agronomia), Universidade Estadual do Maranhão, São Luis, 2003.

CARNEIRO, P.T.; FERNANDES, P.D.; GHEYI, H.R.; SOARES, F.A.L. Germinação e crescimento inicial de genótipos de cajueiro-anão-precoce em condições de salinidade. Revista Brasileira de Engenharia Agrícola e Ambiental, Campina Grande, v.6, n.2, p.199-206, 2002

CAVALCANTI JÚNIOR, A.T.; BARROS, L.M. Jardins clonais e jardins de semente. In: BARROS, L.M.. Caju produção: aspectos técnicos. Fortaleza: EMBRAPACNPAT, 2002. p.95-131

CAVALCANTI JÚNIOR, A.T.; CHAVES, J.C.M. Produção de mudas de cajueiro. Fortaleza: EMBRAPA-CNPAT, 2002. 43p. (Documentos, 42).

CAVALCANTI JÚNIOR, A.T.; CORREA, D.; BUENO, D. Propagação. In: BARROS, L.M.. Caju produção: aspectos técnicos. Fortaleza: EMBRAPA-CNPAT, 2002. p.95-131.

CORRÊA, M.P.F.; CAVALCANTI JUNIOR, A.T.; ALMEIDA, J.I.L.; PEREIRA FILHO, J.E.; GADELHA, J.W R. Propagação vegetativa do cajueiro macropropagação. In: ARAÚJO, J.P.P., SILVA,V.V. (Org.). Cajucultura: modernas técnicas de produção. Fortaleza: EMBRAPA-CNPAT, 1995. p.95-131. 
MAGUIRE, J.D. Speed of germination aid in selection and evaluation for seeding emergence and vigor.

Crop Sciense, Madison, v.2, p.176-177, 1962.
NAKAGAWA, J. Testes de vigor baseado no desempenho das plântulas. In: KRZYZANOWSKI, F.C. et al. Vigor de sementes: conceitos e testes. Londrina: ABRATES, 1999. 218 p. 